\section{Commentary: Optimal treatment of ruptured descending thoracic aortas in the modern era}

\author{
Christopher Lau, MD, and Mario Gaudino, MD
}

Descending thoracic aortic rupture (DTAR) presents a significant challenge to surgeons regardless of whether the surgical approach is endovascular or open surgical repair. Due to the emergent nature of the presentation in these patients, they undergo the lifesaving repair that is most readily available, and the luxury of careful preoperative planning to optimize outcomes is often not available.

Historically, repair of DTAR was associated with an operative mortality as high as $50 \%$, but improvements in technology, surgical technique, and critical care management have improved the operative mortality to $20 \%$ to $25 \%$ in more recent years, with improvements seen in both open and endovascular repairs. ${ }^{1}$ Some of this improvement has been due to the advent of endovascular stent-graft technology and the advantages offered by thoracic endovascular aneurysm repair (TEVAR) cannot be denied. The skill set necessary for successful open surgical repair is highly specialized and not readily available. TEVAR has allowed more patients to be treated in a more expedient fashion owing to the larger number of surgeons in different specialties that can perform this procedure. Clearly, it is easier for a center with less experience in DTAR to achieve better operative outcomes using TEVAR than using open repair.

In this issue of the Journal, Ogawa and colleagues ${ }^{2}$ compare their mid-term outcomes following open versus endovascular repair of ruptured descending thoracic aortas. They compare their historical open repair group to the TEVAR group of the more recent era. Over time, they switched to an exclusively endovascular approach to DTAR. They found that operative mortality was lower and mid-term survival was better with TEVAR compared with open surgical

\footnotetext{
From the Department of Cardiothoracic Surgery, Weill Cornell Medicine, New York, NY.

Disclosures: Authors have nothing to disclose with regard to commercial support.

Received for publication Oct 30, 2019; revisions received Oct 30, 2019; accepted for publication Oct 30, 2019; available ahead of print Nov 27, 2019.

Address for reprints: Mario Gaudino, MD, Department of Cardiothoracic Surgery,

Weill Cornell Medicine, 525 E 68th St, Suite M-404, New York, NY 10065

(E-mail: mfg9004@med.cornell.edu).

J Thorac Cardiovasc Surg 2021;161:2013-4

$0022-5223 / \$ 36.00$

Copyright (c) 2019 by The American Association for Thoracic Surgery

https://doi.org/10.1016/j.jtcvs.2019.10.202
}

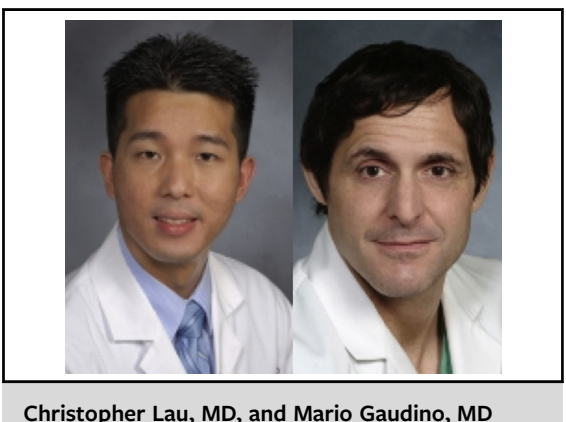

Christopher Lau, MD, and Mario Gaudino, MD

$$
\begin{aligned}
& \text { CENTRAL MESSAGE } \\
& \text { Descending thoracic aortic } \\
& \text { rupture can be reliably repaired } \\
& \text { using both open surgical and } \\
& \text { endovascular techniques, de- } \\
& \text { pending on the experience of the } \\
& \text { surgeon. }
\end{aligned}
$$

repair. However, these findings should be taken with a grain of salt. The 2 groups are from different eras of intraoperative and postoperative care, and, more importantly, the open group was more likely to have thoracoabdominal aneurysms, which is a major confounder given that thoracoabdominal aneurysm was an independent predictor of mortality on logistic regression analysis.

In high-volume centers, open surgical repair of DTAR can achieve results comparable to or better than TEVAR, with operative mortality as low as $14 \%$, better durability, and less need for reintervention and a lower risk of rerupture. ${ }^{3}$ In aortic surgery, we must strive to avoid the "hammer and nail" phenomenon. If an endovascular surgeon is the hammer, then every diseased aorta may start to look like a nail. However, many comorbid conditions and anatomic limitations, especially in patients with aortic dissection, thoracoabdominal aneurysms, or connective tissue disorders, are better suited for an open surgical repair. Our goal should be to repair DTAR with the best suitable option rather than to fit all patients into a single technique. Unfortunately, in the emergent setting of a DTAR and limited availability of open repair options in most hospitals, the repair you get is often what your surgeon knows how to do and not necessarily what you would get in the ideal setting.

\section{References}

1. Kilic A, Shah AS, Black JH 3rd, Whitman GJ, Yuh DD, Cameron DE, et al. Trends in repair of intact and ruptured descending thoracic aortic aneurysms in the United States: a population-based analysis. J Thorac Cardiovasc Surg. 2014;147:1855-60. 

thoracic and thoracoabdominal aortic aneurysms. J Thorac Cardiovasc Surg. midterm out aortic rupture compared with open surgery. J Thorac Cardiovasc Surg. 2021;161: 2004-12.

\section{Commentary: Use it or lose it}

\author{
Kenji Minatoya, MD, PhD
}

The advent of thoracic endovascular aortic repair (TEVAR) has completely changed the therapeutic algorithm for thoracic aortic diseases. The benefits of TEVAR are less invasiveness and the rapidity of the procedure. These features are especially helpful in emergent settings. TEVAR could control lethal bleeding rapidly and save the life of the patient in a catastrophic situation.

In this issue of the Journal, Ogawa and colleagues ${ }^{1}$ report endovascular repair of nontraumatic descending thoracic aortic rupture (DTAR). The majority of the patients were treated by open surgery before 2005 and with TEVAR after 2015. Therefore, an accurate comparison between open repair and TEVAR may be difficult. Further, the longterm fate of the lesion treated with TEVAR is unknown due to a rather short follow-up period after TEVAR.

Yet, the surgical outcomes reported by Ogawa and colleagues with TEVAR for nontraumatic DTAR should be congratulated. Perhaps the excellent outcomes can be attributed to their superb techniques, but also to their fine teamwork. A previous report describing endovascular repair of DTAR by Jonker and colleagues ${ }^{2}$ indicated $15.2 \%$ hospital mortality rate with TEVAR, which is comparable with the current report. Jonker and colleagues ${ }^{2}$ stressed the high stroke rate $(7.6 \%)$ in their report. However, the rate of stroke with TEVAR in the article of Ogawa and colleagues was only $3.8 \%$. In my opinion, this fact indicates that more accumulated know-how of TEVAR for DTAR has improved the outcome.

\footnotetext{
From the Department of Cardiovascular Surgery, Graduate School of Medicine, Kyoto University, Kyoto, Japan.

Disclosures: Author has nothing to disclose with regard to commercial support.

Received for publication Nov 21, 2019; revisions received Nov 21, 2019; accepted for publication Nov 21, 2019; available ahead of print Dec 12, 2019.

Address for reprints: Kenji Minatoya, MD, PhD, 54 Kawarharacho, Shogoin,

Sakyo-ku, Kyoto, 6068507 Japan (E-mail: minatoya@kuhp.kyoto-u.ac.jp).

J Thorac Cardiovasc Surg 2021;161:2014-5

0022-5223/\$36.00

Copyright (c) 2019 by The American Association for Thoracic Surgery

https://doi.org/10.1016/j.jtcvs.2019.11.099
}

\section{5;150:814-21.}

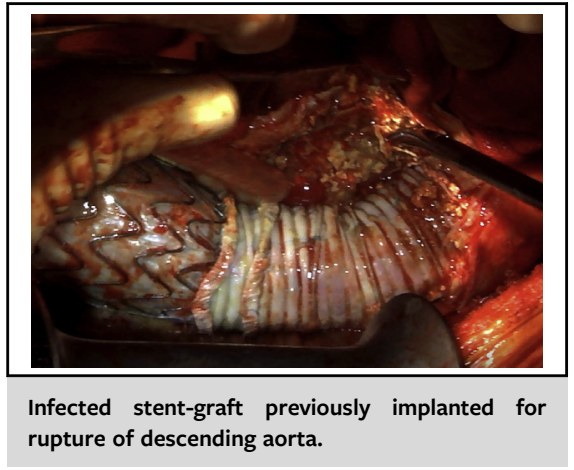

CENTRAL MESSAGE

TEVAR is undoubtedly an excellent procedure to save patients with DTAR; however, we should not cling to a binary choice and should not make a choice only between TEVAR and open surgery.

The study population included 13 aortobronchial fistula (ABFs) or aortoesophageal fistulas. The authors did not describe the procedures of the treatments and the following results minutely; however, TEVAR for $\mathrm{ABF}$ is associated with a high risk of recurrence of $\mathrm{ABF}^{3}$ Accordingly, TEVAR should be used as a bridge to definitive open repair. Bridging TEVAR to open surgery is also a useful adjunct in patients with aortoesophageal fistula with hemorrhagic shock. ${ }^{4}$ The authors described that there was a trend toward increased early and unplanned aortic reintervention in the TEVAR group. The rate of the reintervention was about $20 \%$, and there were several reasons for the reintervention. Yet, the mortality rate in patients requiring unplanned aortic reintervention was $50 \%$. In this point of view, I think early open conversion could be one of the options when initial hemostasis was obtained with TEVAR as the bridge in patients with DTAR.

Although the title of this report indicates the descending aortic rupture, the enrolled population included 12 patients 